\title{
Atributos químicos, físico-hídricos e mineralogia da fração argila em solos do Baixo Amazonas: Serra de Parintins'
}

\author{
Jean Dalmo de Oliveira MARQUES², Wenceslau Geraldes TEIXEIRA ${ }^{3}$, Ana Maria REIS ${ }^{4}$, Orlando Ferreira \\ Cruz JUNIOR ${ }^{5}$, Salomão Marialva BATISTA ${ }^{6}$, Maria Amália Castelo Branco AFONSO7
}

\begin{abstract}
RESUMO
Estudos sobre os atributos dos solos amazônicos geram informaçôes para compor um levantamento atual sobre suas condiçóes frente às várias formas de alteraçóes que estão sujeitos. O objetivo deste trabalho foi descrever e avaliar a evolução química, físicohídrica, bem como a mineralogia de Latossolos no Baixo Amazonas como forma de entender as variaçóes desses atributos em diferentes coberturas vegetais. Coletaram-se amostras deformadas e indeformadas para análises físicas, químicas, mineralógicas e hídricas, em dois pontos de uma topossequência na Serra de Parintins: platô e vertente, sendo três perfis de solo em cada posiçáo. Os resultados obtidos demonstraram que a floresta predominante sobre os perfis do topo e vertente promove condiçóes físicas e hídricas adequadas para uma boa agregação, maior intensidade de poros grandes, maior condutividade hidráulica saturada (Ko) e melhor retenção hídrica dos solos. Fato semelhante ocorrendo com as áreas de capoeira, apresentando boa permeabilidade, porosidade e retençáo de água no solo. O acúmulo de carbono é maior dos perfis da vertente, decrescendo em profundidade, relacionando-se diretamente com Ko e com o sistema radicular. A análise mineralógica da fração argila indicou a caulinita como argilomineral predominante, seguido pelos minerais gibbsita, goethita, quartzo e anatásio, náo havendo variaçóes ao longo da paisagem. A Serra de Parintins possui um solo pobre em nutrientes, ácido, com textura média a muito argilosa com acúmulo de plintita nos horizontes subsuperficiais, evitando o fenômeno de terras caídas. Um gradiente elevado de umidade volumétrica é observado nos horizontes subsuperficiais, havendo mais água retida, quando comparado com horizontes superficiais.
\end{abstract}

PALAVRAS-CHAVE: Serra de Parintins, solos da Amazônia, condutividade hidráulica, retenção de água

\section{Chemical, physical and hydric attributes and mineralogy of clay fractions in soils of lower Amazon: Serra de Parintins}

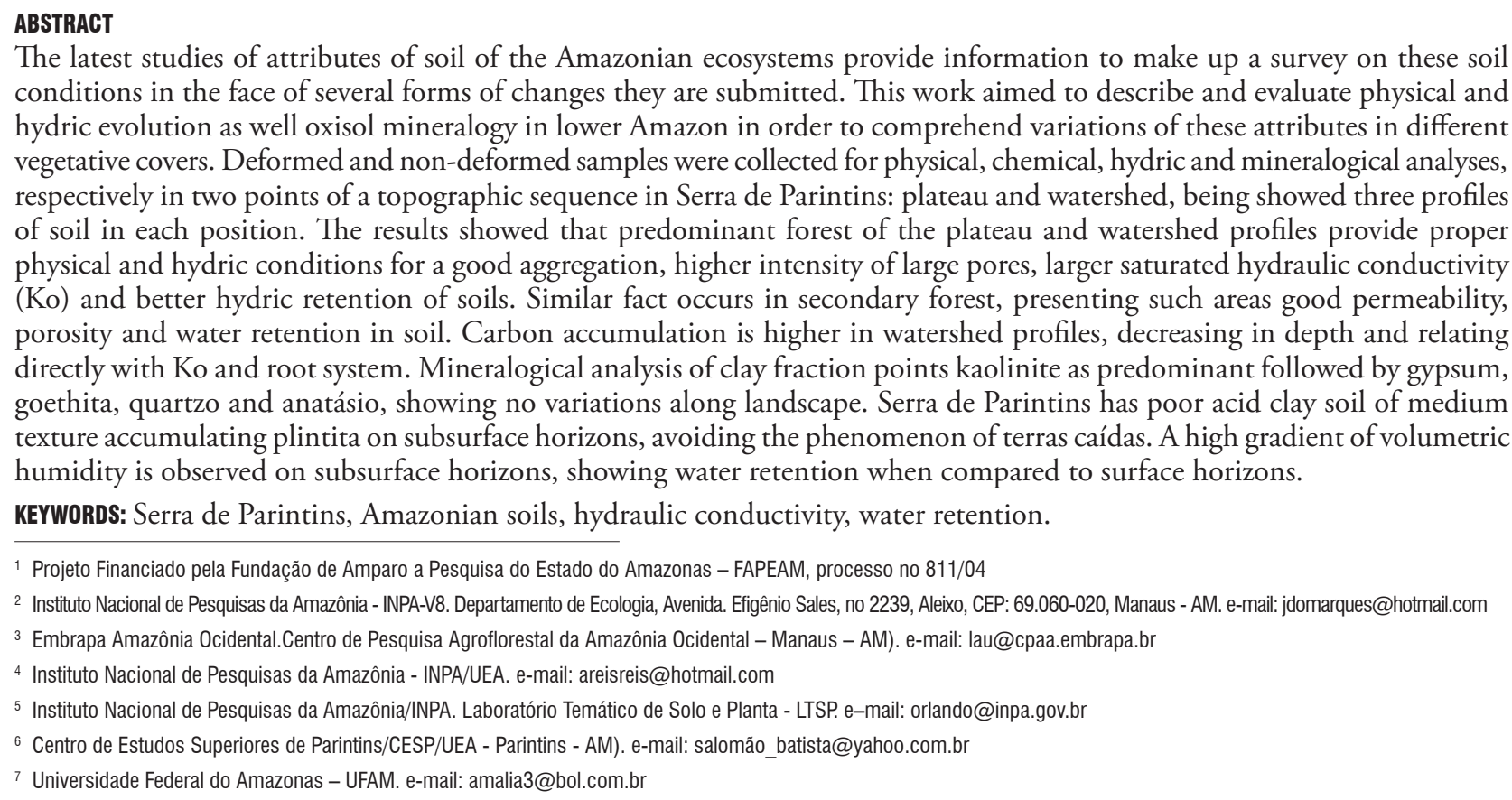

The latest studies of attributes of soil of the Amazonian ecosystems provide information to make up a survey on these soil conditions in the face of several forms of changes they are submitted. This work aimed to describe and evaluate physical and hydric evolution as well oxisol mineralogy in lower Amazon in order to comprehend variations of these attributes in different vegetative covers. Deformed and non-deformed samples were collected for physical, chemical, hydric and mineralogical analyses, respectively in two points of a topographic sequence in Serra de Parintins: plateau and watershed, being showed three profiles of soil in each position. The results showed that predominant forest of the plateau and watershed profiles provide proper physical and hydric conditions for a good aggregation, higher intensity of large pores, larger saturated hydraulic conductivity (Ko) and better hydric retention of soils. Similar fact occurs in secondary forest, presenting such areas good permeability, porosity and water retention in soil. Carbon accumulation is higher in watershed profiles, decreasing in depth and relating directly with Ko and root system. Mineralogical analysis of clay fraction points kaolinite as predominant followed by gypsum, goethita, quartzo and anatásio, showing no variations along landscape. Serra de Parintins has poor acid clay soil of medium texture accumulating plintita on subsurface horizons, avoiding the phenomenon of terras caídas. A high gradient of volumetric humidity is observed on subsurface horizons, showing water retention when compared to surface horizons.

KEYWORDS: Serra de Parintins, Amazonian soils, hydraulic conductivity, water retention.

\footnotetext{
1 Projeto Financiado pela Fundação de Amparo a Pesquisa do Estado do Amazonas - FAPEAM, processo no 811/04

2 Instituto Nacional de Pesquisas da Amazônia - INPA-V8. Departamento de Ecologia, Avenida. Efigênio Sales, no 2239, Aleixo, CEP: 69.060-020, Manaus - AM. e-mail: jdomarques@hotmail.com

3 Embrapa Amazônia Ocidental.Centro de Pesquisa Agroflorestal da Amazônia Ocidental - Manaus - AM). e-mail: lau@cpaa.embrapa.br

${ }^{4}$ Instituto Nacional de Pesquisas da Amazônia - INPA/UEA. e-mail: areisreis@hotmail.com

${ }^{5}$ Instituto Nacional de Pesquisas da Amazônia/INPA. Laboratório Temático de Solo e Planta - LTSP. e-mail: orlando@inpa.gov.br

${ }^{6}$ Centro de Estudos Superiores de Parintins/CESP/UEA - Parintins - AM). e-mail: salomão_batista@yahoo.com.br

7 Universidade Federal do Amazonas - UFAM. e-mail: amalia3@bol.com.br
} 


\section{INTRODUÇÃO}

$\mathrm{Na}$ Amazônia, a interferência humana tem provocado inúmeras mudanças nos processos que controlam a sustentabilidade de seus ecossistemas (Fearnside, 1996), sendo o desmatamento uma ameaça mais grave para a conservação dos recursos naturais, já que provoca distúrbios em vários estágios da regeneração natural, como nas perdas das funçôes da floresta na ciclagem de água (Lean et al, 1996). Todas essas formas de alteração no meio podem alterar as propriedades físico-hídricas do solo. Além disso, pesquisas indicam que o desmatamento leva à perda dos serviços ambientais, que têm um valor maior que os usos pouco sustentáveis que substituem a floresta. Estes serviços incluem a manutençâo da biodiversidade, da ciclagem de água e dos estoques de carbono que evitam o agravamento do efeito estufa (Fearnside, 2006).

O Estado do Amazonas, com 1,6 milhôes de km² apresenta em torno de 90\% de Latossolos e Argissolos distróficos (Vieira \& Santos, 1987). No geral, os solos de terra firme (especificamente o Latossolo Amarelo) sob floresta primária, são pobres em nutrientes, profundos, bem drenados com boa capacidade de retenção de água e permeabilidade, e com baixa CTC (Ferreira, 2006).

$\mathrm{O}$ estudo das relaçôes entre solo e ecossistemas tem se mostrado importante para a compreensão, conservação e manejo dos recursos naturais. $\mathrm{O}$ solo mantido sob vegetação nativa apresenta atributos físicos com permeabilidade, estrutura, densidade e porosidade adequados ao desenvolvimento normal das plantas (Andreola et al., 2004). À medida que o solo sofre mudanças na sua forma, origina alteraçôes desfavoráveis nos seus componentes físicos, no desenvolvimento radicular e armazenamento de água. Uma prática comum na Amazônia é a derrubada e queima da floresta para instalaçấo de roças com culturas anuais e perenes. Depois de no máximo quatro anos de plantio, a produtividade dos cultivos diminui na maioria dos solos, sendo necessário descansá-los com o intuito de melhorar a sua fertilidade e condição física.

O conhecimento das características físicas e hídricas das classes de solo que compóem áreas representativas da Amazônia Central têm avançado lentamente. No passado, alguns estudos foram desenvolvidos em topossequência representativas em sítios experimentais visando caracterizar Latossolos e sua evolução (Bravard \& Righi, 1988; 1991). Mais recentemente, trabalhos sobre atributos físico-hídricos do solo (Tomasella \& Hodnett, 1996; Teixeira, 2001) relatam a importância desses estudos para o conhecimento de impactos e alteraçóes do uso, no ciclo hidrológico e na conservação do solo.

Levando em consideração a importância do conhecimento da dinâmica dos solos amazônicos, o objetivo deste trabalho foi descrever e avaliar a evolução química, físico-hídrica, bem como a mineralogia de Latossolos que compóem a Serra de
Parintins como forma de entender as variaçôes desses atributos em áreas com diferentes coberturas vegetais.

\section{MATERIAL E MÉTODOS}

O presente trabalho foi conduzido no Município de Parintins, Lago da Valéria, em solos situados na Serra de Parintins (Quadro 1).

Quadro 1 - Localização dos perfis de solos amostrados

\begin{tabular}{|c|c|c|c|c|}
\hline Perfis & $\begin{array}{l}\text { Tipo de } \\
\text { Solo }\end{array}$ & Posição & Vegetação & $\begin{array}{c}\text { Coordenadas } \\
\text { Geográficas }\end{array}$ \\
\hline P1 & LAd & Platô & Floresta densa & $\begin{array}{c}02^{\circ} 26^{\prime} 43^{\prime \prime} \mathrm{S} \mathrm{e} \\
56^{\circ} 26^{\prime} 52^{\prime \prime} \mathrm{W}\end{array}$ \\
\hline $\mathrm{P} 2$ & LAd & Platô & Capoeira - 7 anos & $\begin{array}{c}02^{\circ} 26^{\prime} 45^{\prime \prime} \mathrm{S} \mathrm{e} \\
56^{\circ} 26^{\prime} 53^{\prime \prime} \mathrm{W}\end{array}$ \\
\hline P3 & LAd & Platô & Capoeira - 3 anos & $\begin{array}{c}02^{\circ} 26^{\prime} 57^{\prime \prime} \mathrm{S} \mathrm{e} \\
56^{\circ} 26^{\prime} 51^{\prime \prime} \mathrm{W}\end{array}$ \\
\hline P4 & LVd & Vertente & Floresta aberta & $\begin{array}{c}02^{\circ} 27^{\prime} 07^{\prime \prime} \mathrm{S} \text { e } \\
56^{\circ} 26^{\prime} 54^{\prime \prime} \mathrm{W}\end{array}$ \\
\hline P5 & LVda & Vertente & Floresta aberta & $\begin{array}{c}02^{\circ} 27^{\prime} 07^{\prime \prime} \mathrm{S} \mathrm{e} \\
56^{\circ} 26^{\prime} 53^{\prime \prime} \mathrm{W}\end{array}$ \\
\hline P6 & $\mathrm{LVd}$ & Vertente & Floresta aberta & $\begin{array}{c}02^{\circ} 27^{\prime} 05^{\prime \prime} \mathrm{S} \mathrm{e} \\
56^{\circ} 26^{\prime} 57^{\prime \prime} \mathrm{W}\end{array}$ \\
\hline
\end{tabular}

Os perfis estudados apresentam diferentes coberturas vegetais (floresta densa, capoeira com sete anos, capoeira com 1 ano e floresta aberta) apresentan variaçóes na textura, densidade, porosidade e na química do solo em função da posição na paisagem. Segundo a classificação de Koppen, o clima da região é do tipo Afi, caracterizado por apresentar precipitação média anual de $2420 \mathrm{~mm}$, com $295 \mathrm{~mm}$ mensais, de março a abril, e $105 \mathrm{~mm}$ mensais, de agosto a setembro (Embrapa, 1984).

Seis perfis foram abertos ao longo de uma evolução de solos, com dimensão de $1,5 \mathrm{~m} \times 1,5 \mathrm{~m} \times 1,5 \mathrm{~m}$ para a descriçáo morfológica (Lemos \& Santos, 1996), e sua classificação foi baseada no Sistema Brasileiro de Classificação de Solos (Embrapa, 1999). Coletaram-se amostras com estrutura deformada ao longo dos horizontes pedogenéticos identificados; para as determinaçóes físicas e químicas até 1,5 $m$ de profundidade. A densidade do solo $(\rho)$ foi determinada a partir de amostras indeformadas, utilizando anéis volumétricos. A determinação da densidade de partículas foi realizada pelo método do picnômetro, conforme metodologia descrita no manual de métodos de análise físicas da Embrapa (1997).

A análise granulométrica foi realizada pelo método da pipeta (Embrapa, 1997), utilizando-se $50 \mathrm{~g}$ de solo. As amostras foram dispersas em soluçôes aquosas de pirofosfato de sódio $\left(6 \mathrm{~kg} \mathrm{~m}^{-3}\right)$ e hidróxido de sódio $\left(4 \mathrm{~kg} \mathrm{~m}^{-3}\right)$, por agitação lenta durante $16 \mathrm{~h}$. As fraçôes grosseiras (areia fina e grossa) foram separadas por tamisaçáo, secas em estufa e pesadas para obtenção dos respectivos percentuais. $\mathrm{O}$ silte corresponde 
ao complemento dos percentuais para $100 \%$, foi obtido por diferença das outras fraçóes em relação à amostra original.

A mineralogia da fração argila foi caracterizada por difraçáo de raios-X (DRX), com auxílio do equipamento SHIMADZU - XRD 6000. A fração argila foi submetida à ultrason para desagregar aquelas presas aos grãos de quartzo. As amostras foram previamente submetidas à eliminação da matéria orgânica e óxidos de ferro, adicionando-se $\mathrm{H}_{2} \mathrm{O}_{2}$, por um tempo de $30 \mathrm{~h}$. Cada amostra foi centrifugada três vezes. Com a fração argila separada, procedeu-se a pipetagem para confeccionar as lâminas para análise. A análise de DRX teve um tempo de $1 \mathrm{~h}$ e 20 min por amostra, com leitura de varredura ${ }^{\circ} 2 \theta /$ min com leituras entre $5^{\circ}$ e $65^{\circ}$.

As análises químicas foram: $\mathrm{pH}$ em água, $\mathrm{P}, \mathrm{K}, \mathrm{Ca}, \mathrm{Na}, \mathrm{Mg}$, $\mathrm{Al}, \mathrm{C}, \mathrm{N}, \mathrm{Fe}, \mathrm{Zn}, \mathrm{Mn}$, Cu e matéria orgânica (Embrapa, 1999). A determinação do fósforo disponível foi realizada através de método colorimétrico, empregando espectrofotômetro UV visível 1240, marca SHIMADZU, sendo a extração realizada com solução duplo-ácido ( $\mathrm{HCl}$ 0,05 M + H2SO4 0,0125 M). Os elementos potássio, cálcio e magnésio foram determinados por espectrofotometria de absorção atômica; a extração desses elementos foi realizada com duplo ácido e $\mathrm{KCl} 1 \mathrm{~N}$.

O estudo da retenção foi realizado a partir da coleta de amostras com estrutura indeformada que foram coletadas com auxílio de amostrador tipo Uhland, com anéis volumétricos de $0,05 \mathrm{~m}$ de altura e $0,05 \mathrm{~m}$ de diâmetro. Cada uma das amostras foi submetida às tensóes: $1,2,3,4,6,10,30$, 50, 100, 500 e $1500 \mathrm{kPa}$. Os equipamentos utilizados na determinação da curva de retenção foram a mesa de tensão (Embrapa, 1997), com a qual foram obtidas as tensóes 1, 2, 3,4 e $6 \mathrm{kPa}$, e câmaras de pressáo, para as tensões 10, 30, 50, 100, 500 e $1500 \mathrm{kPa}$. Após o equilíbrio, as amostras foram pesadas, determinando-se, posteriormente, o seu conteúdo de água.

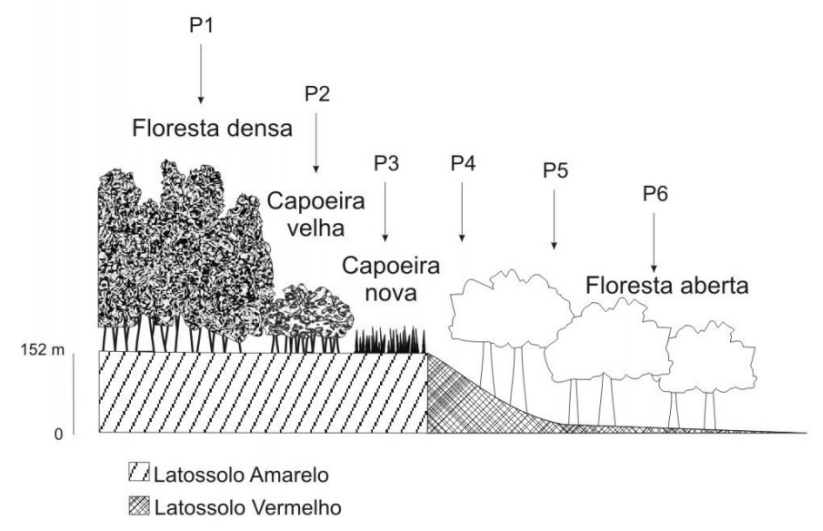

Figura 1 - Esquema demonstrativo da classe de solo e cobertura vegetal predominante na topossequência.
O método para determinar a permeabilidade (Ko) foi o do permeâmetro de carga constante (Youngs, 1991), utilizandose amostras indeformadas, sendo coletado um total de 125 amostras, sendo 05 amostras em cada horizonte pedológico. Utilizou-se um amostrador de solo tipo Uhland, com anéis volumétricos, de $0,072 \mathrm{~m}$ de altura e $0,069 \mathrm{~m}$ de diâmetro.

A análise do comportamento hidráulico no solo também foi realizada dentro de cada horizonte. As análises estatísticas foram efetuadas com a utilização do Programa Systat 8.0 (Wikinson, 1998).

\section{RESULTADOS E DISCUSSÃO}

As Tabelas 1 e 2 apresentam os resultados das análises físicas e químicas dos solos ao longo da topossequência. $\mathrm{O}$ teor de matéria orgânica decresce em profundidade (Tabela 2), sendo o seu maior conteúdo encontrado na superfície devido à incorporaçáo de resíduos vegetais no solo, refletindo nos maiores valores de fósforo e soma de bases na superfície. Os níveis de $\mathrm{Na}^{+1}$, Ca, Mg, K e P (Tabela 2) foram baixos, provavelmente devido ao intemperismo sobre esta região (Jordan, 1986). A diminuição da matéria orgânica em profundidade deve ser um dos fatores que interferem nos valores de densidade do solo (Tabela 1). A capacidade de troca de cátions (T) decresceu em profundidade, em todos os perfis (Tabela 2). Observa-se, ainda, baixa saturação por base (V\%) e alta saturaçáo por alumínio (m), fato comum em solos originados desses sedimentos argilosos. Os maiores teores de $\mathrm{P}$ e $\mathrm{K}$ foram observados nos perfis da vertente (Tabela 2), provavelmente, em função da cobertura vegetal e intensidade de raízes (Tabela 3). Um das fontes de $\mathrm{K}$ são os exudatos de raízes em sistemas cobertos por vegetação (Stallard \& Edmond, 1981). O ânion fosfato também tem a sua origem a partir de componentes terrestres, derivados de partículas biológicas, como exudatos de raízes e reciclagem da serrapilheira (Berner \& Berner, 1987).

A análise granulométrica revelou heterogeneidade na distribuição do tamanho das partículas, havendo aumento no teor de argila com a profundidade em todos os perfis estudados (Tabela 1). Os perfis foram classificados como de textura argilosa nos horizontes dos Latossolos Amarelos e textura média na superfície do Latossolo Vermelho argissólico e Latossolo Vermelho, evoluindo para argilosa e muito argilosa, nas maiores profundidades (Tabela 3). Os valores de densidade do solo $(\rho)$ apresentaram comportamento similar ao da textura, com aumento em profundidade, sendo os menores valores encontrados nas camadas superficiais dos solos sob ambiente de floresta aberta (Tabela 1).

Pelas descrições macromorfológicas (Tabela 3), os perfis demonstram estruturação fraca a moderada, sendo forte no P6 em decorrência da presença da laterita. A consistência desses Latossolos variou de macio a dura, quando secos, muito friável e friável, quando úmidos; não plástico, plástico, ligeiramente 
Tabela 1 - Distribuição granulométrica, densidade dos sólidos e do solo, porosidade nos horizontes dos perfis da topossequência, Serra de Parintins-AM.

\begin{tabular}{|c|c|c|c|c|c|c|c|c|c|c|c|c|}
\hline \multirow[b]{2}{*}{ Prof. (m) } & \multirow[b]{2}{*}{ Hor } & \multicolumn{3}{|c|}{ Areia } & \multirow[b]{2}{*}{ Silte } & \multirow[b]{2}{*}{ Argila Total } & \multirow[b]{2}{*}{$\rho$} & \multirow[b]{2}{*}{$\rho_{\mathrm{s}}$} & \multicolumn{3}{|c|}{ Porosidade } & \multirow{2}{*}{$\begin{array}{l}\text { Condutividade } \\
\text { Hidráulica } \\
\text { Saturada * (Ko }\end{array}$} \\
\hline & & Grossa & Fina & Total & & & & & Total & $\mathrm{Ma}$ & Mi & \\
\hline & & \multicolumn{2}{|c|}{$\mathrm{g} \mathrm{kg}^{-1}$} & & \multicolumn{2}{|c|}{$\mathrm{g} \mathrm{kg}^{-1}$} & \multicolumn{2}{|c|}{$\mathrm{kg} \mathrm{m}^{-3}$} & & $\mathrm{~m} 3 \mathrm{~m}^{-3}$ & & $\left(\mathrm{~cm} \cdot \mathrm{dia}^{-1}\right)$ \\
\hline \multicolumn{13}{|c|}{ P1 - LAd - Latossolo Amarelo distrófico - Floresta densa - Platô } \\
\hline $0,00-0,16$ & A1 & 10,8 & 8,7 & 19,5 & 149,5 & 831 & 670 & 2320 & 0,71 & 0,35 & 0,36 & $3,34 a \pm 0,15$ \\
\hline $0,16-0,46$ & $A B$ & 8,2 & 9,2 & 17,5 & 129,5 & 853 & 900 & 2470 & 0,63 & 0,25 & 0,38 & $2,89 b \pm 0,09$ \\
\hline $0,46-0,65$ & Bw1 & 7,8 & 7,8 & 15,7 & 97,3 & 887 & 1040 & 2470 & 0,58 & 0,18 & 0,40 & $2,65 c \pm 0,19$ \\
\hline $0,65-1,50+$ & Bw2 & 9,8 & 5,1 & 14,9 & 65,0 & 920 & 1130 & 2500 & 0,55 & 0,14 & 0,41 & $2,80 \mathrm{~b} \pm 0,07$ \\
\hline \multicolumn{13}{|c|}{ P2 - LAd - Latossolo Amarelo distrófico - Capoeira velha 7 anos - Platô } \\
\hline $0,00-0,30$ & $\mathrm{~A} 1$ & 126,4 & 12,5 & 138,9 & 116,1 & 745,0 & 782 & 2708 & 0,71 & 0,32 & 0,38 & $3,38 a \pm 0,12$ \\
\hline $0,30-0,48$ & $A B$ & 17,9 & 9,41 & 27,3 & 232,2 & 740,5 & 1025 & 2601 & 0,60 & 0,21 & 0,39 & $2,94 b \pm 0,11$ \\
\hline $0,48-1,10^{+}$ & Bw1 & 21,1 & 10,0 & 31,2 & 58,8 & 910,0 & 1001 & 2587 & 0,61 & 0,24 & 0,36 & $2,85 c \pm 0,23$ \\
\hline \multicolumn{13}{|c|}{ P3 - LAd - Latossolo Amarelo distrófico - Capoeira nova (3 anos) - Platô } \\
\hline $0,00-0,20$ & A1 & 65 & 73,8 & 138,8 & 258,7 & 602,5 & 800 & 2760 & 0,65 & 0,30 & 0,35 & $3,63 a \pm 0,09$ \\
\hline $020-0,62$ & $A B$ & 18,1 & 7,2 & 25,3 & 314,7 & 660,0 & 1060 & 2500 & 0,60 & 0,20 & 0,40 & $3,53 b \pm 0,13$ \\
\hline $0,62-1,20 w$ & Bw1 & 12,0 & 16,4 & 28,4 & 101,5 & 870,0 & 1000 & 2480 & 0,50 & 0,20 & 0,30 & $2,86 \mathrm{c} \pm 0,10$ \\
\hline \multicolumn{13}{|c|}{ P4 - LVd -Latossolo Vermelho distrófico - Floresta aberta - terço superior da vertente } \\
\hline $0,00-0,25$ & A1 & 160,2 & 108,1 & 268,4 & 417,6 & 314,0 & 454 & 2577 & 0,82 & 0,48 & 0,33 & $3,45 a \pm 0,17$ \\
\hline $0,25-0,60$ & A2 & 79,1 & 66,4 & 145,5 & 428 & 426,5 & 457 & 2730 & 0,83 & 0,47 & 0,36 & $3,26 a \pm 0,13$ \\
\hline $0,60-1,02$ & BA & 137,6 & 63,2 & 201 & 290,7 & 508,5 & 632 & 2700 & 0,76 & 0,43 & 0,33 & $3,49 a \pm 0,06$ \\
\hline $1,02-1,52$ & Bw1 & 136,9 & 42,6 & 179,6 & 129,9 & 690,5 & 1051 & 2570 & 0,59 & 0,26 & 0,32 & $2,75 b \pm 0,07$ \\
\hline $1,52-2,00^{+}$ & Bw2 & 148,1 & 37,4 & 185,6 & 108,4 & 706,0 & 1170 & 2710 & 0,56 & 0,21 & 0,35 & $2,79 b \pm 0,05$ \\
\hline \multicolumn{13}{|c|}{ P5 - LVda - Latossolo Vermelho distrófico argissólico - Floresta aberta - terço médio da vertente } \\
\hline $0,00-0,20$ & A1 & 128,6 & 81,7 & 210,3 & 491,2 & 298,5 & 457 & 2684 & 0,82 & 0,46 & 0,36 & $3,78 a \pm 0,07$ \\
\hline $0,20-0,33$ & A2 & 162,6 & 122,2 & 284,9 & 410,1 & 305,0 & 485 & 2624 & 0,81 & 0,42 & 0,39 & $3,83 a \pm 0,18$ \\
\hline $0,33-1,05$ & BA & 122,0 & 83,4 & 205,5 & 350,5 & 444,0 & 691 & 2720 & 0,74 & 0,32 & 0,41 & $3,39 a \pm 0,11$ \\
\hline $1,05-1,77$ & Bw1 & 170,0 & 41,4 & 211,4 & 126,5 & 662,0 & 880 & 2660 & 0,66 & 0,27 & 0,39 & $2,70 b \pm 0,05$ \\
\hline $1,77-2,20^{+}$ & Bw2 & 179,2 & 47,4 & 226,7 & 120,3 & 653,0 & 1392 & 2667 & 0,48 & 0,08 & 0,40 & $2,38 c \pm 0,48$ \\
\hline \multicolumn{13}{|c|}{ P6 - LVd -Latossolo Vermelho distrófico - Floresta aberta - terço inferior da vertente } \\
\hline $0,00-0,18$ & A1 & 377,7 & 131,2 & 509 & 149,0 & 342,0 & 1280 & 2668 & 0,52 & 0,17 & 0,35 & $3,52 \mathrm{a} \pm 0,36$ \\
\hline $0,18-0,28$ & BA & 316,5 & 131,3 & 447,7 & 163,7 & 388,5 & 1390 & 2613 & 0,47 & 0,15 & 0,32 & $2,90 \mathrm{~b} \pm 0,31$ \\
\hline $0,28-0,58$ & Bw1 & 307,0 & 113,7 & 420,7 & 146,2 & 433,0 & 1480 & 2667 & 0,53 & 0,20 & 0,34 & $3,29 a \pm 0,24$ \\
\hline $0,58-0,96$ & Bw2 & 292,0 & 133,0 & 425,0 & 99,9 & 475,0 & 1510 & 2686 & 0,46 & 0,14 & 0,32 & $2,47 c \pm 0,11$ \\
\hline $0,96-1,80^{+}$ & Bw3 & 362,7 & 141,2 & 504 & 75,0 & 421,0 & 1590 & 2629 & 0,44 & 0,14 & 0,30 & $3,03 a \pm 0,42$ \\
\hline
\end{tabular}

$\mathrm{Ma}=$ macroporosidade; $\mathrm{Mi}=$ microporosidade; $\rho=$ densidade do solo; $\rho \mathrm{s}=$ densidade das partículas

*Médias com letras distintas, na coluna, diferem, por horizontes, pelo teste de Tukey a 5\% de probabilidade.

plástico, muito plástico e náo pegajoso, pegajoso, ligeiramente pegajoso, quando molhados. As transiçóes foram variáveis entre gradual e difusa, predominantemente horizontal. A comparação entre as características macromorfológicas dos seis perfis pode refletir, em parte, seus posicionamentos no relevo, o que demonstra diferentes condiçôes de drenagem dos solos. Neste caso, as cores amareladas nos perfis P1, P2 e P3 situados na parte mais elevada, e avermelhada nos perfis P4, P5 e P6, refletem condiçóes diferenciadas de drenagem.

A análise mineralógica da fração argila indicou a caulinita como argilomineral predominante, seguido pela gibbsita, goethita, quartzo e anatásio (Figuras 2 a 4). Não houve variaçôes na mineralogia ao longo da paisagem, já que as áreas de topo e vertente apresentaram boa permeabilidade
(Tabela 1), podendo ser uma característica para a presença desses minerais. A natureza caulinítica destes solos já era esperada, uma vez que eles pertencerem a Formaçáo Alter do Cháo, apresentando uma litologia sedimentar terciária, evidenciando Latossolo Amarelo, onde se instalou a floresta densa. Latossolos cauliníticos são normalmente mais microagregados, com as partículas granulares menos arredondadas e mais parecidas com blocos (Schaefer, 1996), conforme observado neste estudo. Para Lucas et al. (1993), o predomínio de caulinita sobre gibbsita em solos da Amazônia deve-se a intensa reciclagem de silício pela vegetação florestal, favorecendo a estabilidade da caulinita, mesmo em ambiente altamente intemperizado. 


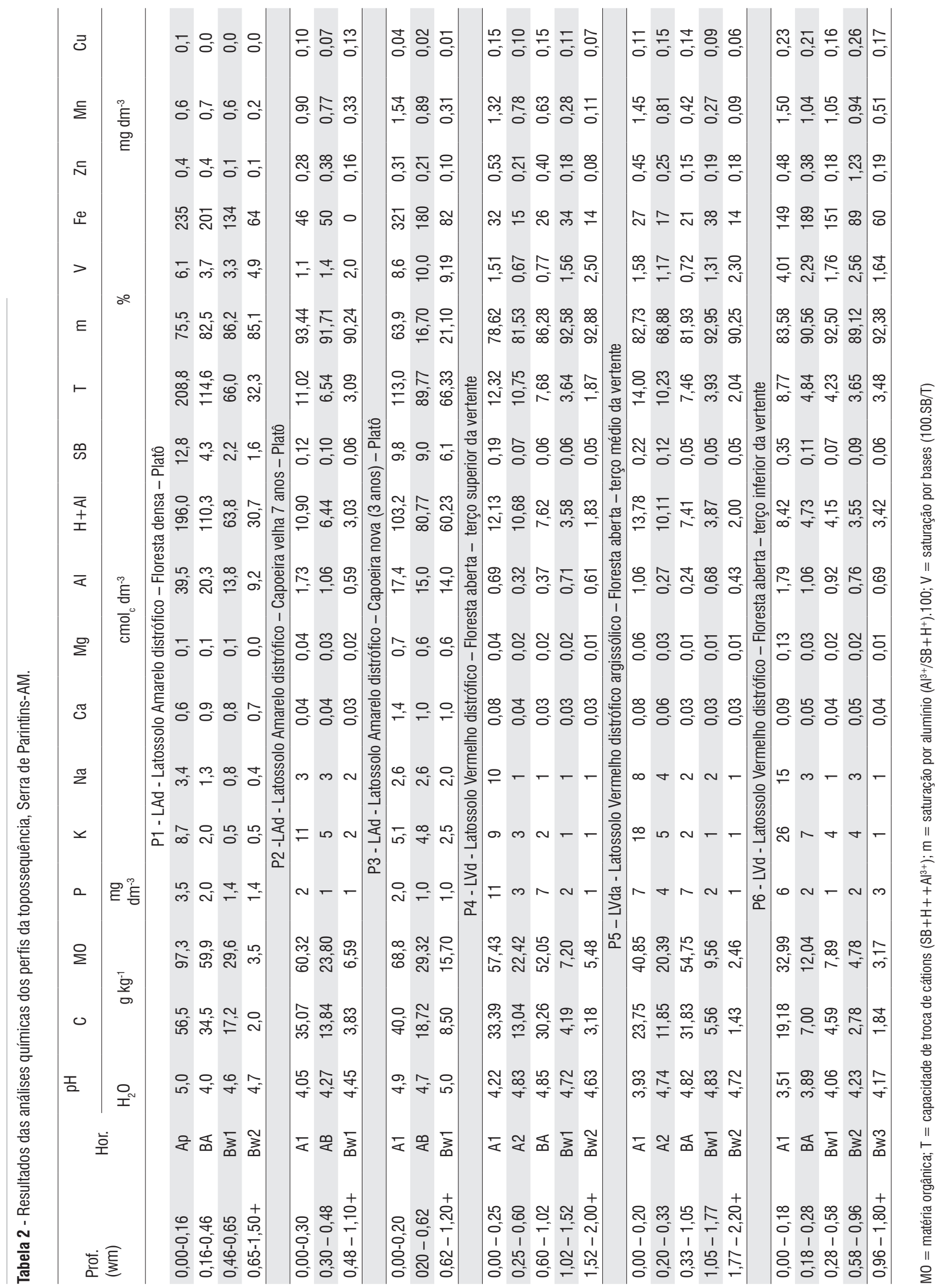


Tabela 3 - Caracterização macromorfológica dos perfis estudados, topossequências, Serra de Parintins - AM

\begin{tabular}{|c|c|c|c|c|c|c|c|c|}
\hline Prof. $(\mathrm{m})$ & Hor & Textura & $\begin{array}{l}\text { Cor } \\
\text { úmida }\end{array}$ & $\begin{array}{c}\text { Estrutura } \\
\text { tipo, classe, grau }\end{array}$ & $\begin{array}{c}\text { Consistência } \\
\text { seca, úmida, molhada }\end{array}$ & Porosidade & Raízes & Transição \\
\hline \multicolumn{9}{|c|}{ P1 - LAd - Latossolo Amarelo distrófico - Floresta densa - Platô } \\
\hline $0,00-0,16$ & Ap & M.argilosa & $\begin{array}{c}10 Y R \\
4 / 4\end{array}$ & $\begin{array}{l}\text { bl. sub., peq. e média, } \\
\text { moderada }\end{array}$ & $\begin{array}{l}\text { lig. dura, friável, pl. e } \\
\text { pegajoso }\end{array}$ & m. gr., p. peq. & c.gr. e peq finas. finas & Grad.e Horiz. \\
\hline $0,16-0,46$ & BA & M.argilosa & $\begin{array}{l}10 Y R \\
7 / 6\end{array}$ & $\begin{array}{l}\text { bl. sub., peq. e média, } \\
\text { fraca }\end{array}$ & macio, friável, pl. e peg. & m. gr., p. peq. & c.gr. e c. peq finas & Dif. e Hor. \\
\hline $0,46-0,65$ & Bw1 & M.argilosa & $\begin{array}{c}10 Y R \\
7 / 7\end{array}$ & $\begin{array}{l}\text { bl. sub., peq. e média, } \\
\text { fraca }\end{array}$ & macio, friável, pl. e peg. & p. gr. e m. peq. & r. gr., c. peq. finas & Dif. e Hor. \\
\hline $65-1,50$ & Bw2 & M.argilosa & $\begin{array}{c}10 Y R \\
7 / 8\end{array}$ & $\begin{array}{l}\text { bl. sub., peq. e média, } \\
\text { fraca }\end{array}$ & $\begin{array}{l}\text { macio, friável, plástico e } \\
\text { pegajoso }\end{array}$ & r. gr. e m. peq. & r.gr., ab. peq. finas & Dif. e Hor. \\
\hline \multicolumn{9}{|c|}{ P2 - LAd - Latossolo Amarelo distrófico - Capoeira 7 anos - Platô } \\
\hline $0,00-0,30$ & A & M.argilosa & $\begin{array}{c}10 Y R \\
4 / 3\end{array}$ & $\begin{array}{l}\text { bl. sub., peq. e média, } \\
\text { moderada }\end{array}$ & $\begin{array}{l}\text { lig. dura, friável, não pl., } \\
\text { lig. peg. }\end{array}$ & c. peq. e gr. & ab.peq finas., p. gr & Grad. \\
\hline $0,30-0,48$ & $A B$ & M.argilosa & $\begin{array}{l}10 Y R \\
4 / 4\end{array}$ & $\begin{array}{l}\text { bl. sub., peq. e média, } \\
\text { moderada }\end{array}$ & $\begin{array}{l}\text { lig. dura, friável, lig. pl., } \\
\text { lig. peg. }\end{array}$ & m. peq., p. gr. & p.peq finas., p. gr. & Clara e Hor. \\
\hline $48-1,10$ & Bw1 & M.argilosa & $\begin{array}{c}10 Y R \\
7 / 8\end{array}$ & $\begin{array}{l}\text { bl. sub., peq. e média, } \\
\text { fraca }\end{array}$ & lig. dura, m.friável, pl, peg. & m. peq., p. gr. & r. peq finas., r. gr. & Dif. e Hor. \\
\hline \multicolumn{9}{|c|}{ P3 -LAd - Latossolo Amarelo distrófico - Capoeira nova (3 anos) - Platô } \\
\hline $0,00-0,20$ & A & M.argilosa & $\begin{array}{c}10 Y R \\
4 / 4\end{array}$ & $\begin{array}{l}\text { bl. sub., peq. e média, } \\
\text { moderada }\end{array}$ & $\begin{array}{l}\text { lig. dura, friável, não pl., } \\
\text { lig. peg. }\end{array}$ & c. peq. e méd. & ab.peq finas., p. gr & Grad. e Horiz. \\
\hline$, 20-0,62$ & $A B$ & M.argilosa & $\begin{array}{c}10 Y R \\
4 / 3\end{array}$ & $\begin{array}{l}\text { bl. sub., peq. e média, } \\
\text { moderada }\end{array}$ & $\begin{array}{r}\text { lig. dura, friá } \\
\text { lig. } p e\end{array}$ & n. peq., p. gr. & p.peq finas., p. gr. & Clara e Horiz. \\
\hline $32-1,20+$ & Bw1 & M.argilosa & $\begin{array}{c}10 Y R \\
7 / 7\end{array}$ & $\begin{array}{l}\text { bl. sub., peq. e média, } \\
\text { fraca }\end{array}$ & g. dura, m.friável, pl, peg. & m. peq., r. gr. & r. peq finas., r. gr. & Dif. e Hor. \\
\hline \multicolumn{9}{|c|}{ P4 - LVd - Latossolo Vermelho distrófico - Floresta aberta - terço superior da vertente } \\
\hline $0,00-0,25$ & A1 & Média & $\begin{array}{c}2,5 \mathrm{YR} \\
3 / 2\end{array}$ & bl. sub., m. peq., fraca & $\begin{array}{l}\text { macio, friável, n-plástico, } \\
\text { n-peg. }\end{array}$ & c.gr., p.peq. & $\begin{array}{l}\text { ab. peq. finas, r.méd.; } \\
\text { c.gr }\end{array}$ & Grad. e Hor. \\
\hline $25-0,60$ & A2 & Argilosa & $\begin{array}{c}2,5 \mathrm{YR} \\
3 / 2\end{array}$ & bl. sub., m. peq., fraca & $\begin{array}{l}\text { macio, friável, n-plástico, } \\
\text { n-peg. }\end{array}$ & m.gr., p.peq. & $\begin{array}{l}\text { ab. finas, r. méd., } \\
\text { p.gr. }\end{array}$ & Grad. e Hor. \\
\hline $0,60-1,02$ & BA & Argilosa & $\begin{array}{c}2,5 \mathrm{YR} \\
3 / 6\end{array}$ & bl. sub., peq., fraca & $\begin{array}{r}\text { macio, friáve } \\
n-p\end{array}$ & $\begin{array}{r}\text { C. } m \\
\text { con }\end{array}$ & r. peq.; p. méd.; r. gr. & Grad. e Hor. \\
\hline $1,02-1,52$ & Bw1 & M.argilosa & $\begin{array}{c}2,5 Y R \\
5 / 8\end{array}$ & I. sub., peq., moderada & $\begin{array}{l}\text { lig.duro } \\
\text { plásticc }\end{array}$ & $\begin{array}{l}\text { c. peq.; r. gr. e } \\
\text { méd. }\end{array}$ & p. peq., p. méd., r. gr. & Dif. e Hor. \\
\hline$, 52-2,00+$ & Bw2 & M.argilosa & $\begin{array}{c}2,5 Y R \\
5 / 8\end{array}$ & $\begin{array}{l}\text { bl. sub., média, } \\
\text { moderada }\end{array}$ & $\begin{array}{l}\text { lig.duro, m.friável, } \\
\text { plástico, peg. }\end{array}$ & $\begin{array}{l}\text { c.peq.; r.gr e } \\
\text { méd. }\end{array}$ & r. peq., méd. e gr. & Dif. e Hor. \\
\hline \multicolumn{9}{|c|}{ P5 - LVda - Latossolo Vermelho distrófico argissólico - Floresta aberta - terço médio da vertente } \\
\hline $0,00-0,20$ & A1 & Média & $\begin{array}{l}2,5 \mathrm{YR} \\
2 / 2\end{array}$ & bl. sub., pequena, fraca & $\begin{array}{l}\text { macio, friável, lig.plástico, } \\
\text { lig. pegajoso }\end{array}$ & c.gr., p.peq. & $\begin{array}{l}\text { ab.peq fina } \\
\text { p. }\end{array}$ & Dif. e Hor. \\
\hline $0,20-0,33$ & A2 & Média & $\begin{array}{c}2,5 \mathrm{YR} \\
3 / 2\end{array}$ & bl. sub., média, fraca & $\begin{array}{l}\text { lig.duro; friá } \\
\text { plástico, lig. I }\end{array}$ & m.gr., p.peq. & c.méd.; p.peq., r.gr. & Dif. e Hor. \\
\hline $0,33-1,05$ & BA & Argilosa & $\begin{array}{c}2,5 \mathrm{YR} \\
3 / 4\end{array}$ & bl. sub., média, fraca & $\begin{array}{l}\text { lig.duro; friá } \\
\text { plástico, lig. I }\end{array}$ & $\begin{array}{l}\text { c. méd. e gr.; } \\
\text { com. peq. }\end{array}$ & p.peq., p.méd., r.gr. & Grad. e Hor. \\
\hline $1,05-1,77$ & Bw1 & M.argilosa & $\begin{array}{c}2,5 Y R \\
4 / 8\end{array}$ & $\begin{array}{l}\text { bl. sub., média, } \\
\text { moderada }\end{array}$ & $\begin{array}{l}\text { duro; firme; plástico; } \\
\text { pegajoso }\end{array}$ & $\begin{array}{l}\text { c. peq.; r. gr. e } \\
\text { méd. }\end{array}$ & p.peq., p.gr., r.méd. & Clara e Hor. \\
\hline $77-2,20+$ & Bw2 & M.argilosa & $\begin{array}{c}2,5 \mathrm{YR} \\
5 / 8\end{array}$ & bl. sub., média, forte & $\begin{array}{l}\text { duro, firme, m. plástico, } \\
\text { m.pegajoso }\end{array}$ & $\begin{array}{l}\text { c.peq.; r.gr e } \\
\text { méd. }\end{array}$ & p.peq., r.méd. e gr. & Dif. e Hor. \\
\hline \multicolumn{9}{|c|}{ P6 - LVd - Latossolo Vermelho distrófico - Floresta aberta - terço inferior da vertente } \\
\hline $0,00-0,18$ & A & Média & $\begin{array}{c}2,5 Y R \\
4 / 6\end{array}$ & $\begin{array}{l}\text { bl. sub. peq e m. peq., } \\
\text { moderada }\end{array}$ & $\begin{array}{l}\text { lig.duro, friável, lig. } \\
\text { plástico, lig. pegajoso }\end{array}$ & c.gr., p.peq. & $\begin{array}{l}\text { ab.peq finas e méd., } \\
\text { p. gr. }\end{array}$ & Grad. e Hor. \\
\hline $0,18-0,28$ & BA & Média & $\begin{array}{l}2,5 \mathrm{YR} \\
4 / 6\end{array}$ & $\begin{array}{l}\text { bl. sub. peq e média, } \\
\text { moderada }\end{array}$ & $\begin{array}{l}\text { lig.duro, friável, plástico, } \\
\text { lig. pegajoso }\end{array}$ & m.gr., p.peq. & c.méd.; p.peq., r.gr. & Grad. e Hor. \\
\hline $0,28-0,58$ & Bw1 & Argilosa & $\begin{array}{c}2,5 \mathrm{YR} \\
5 / 8\end{array}$ & $\begin{array}{l}\text { bl. sub. peq. e média, } \\
\text { forte }\end{array}$ & $\begin{array}{c}\text { duro, friável, plástico, lig. } \\
\text { pegajoso }\end{array}$ & $\begin{array}{l}\text { c. méd. e gr.; } \\
\text { com. peq. }\end{array}$ & p.peq., p.méd., r.gr. & Dif. e Hor. \\
\hline $0,58-0,96$ & Bw2 & Argilosa & $\begin{array}{l}2,5 \mathrm{YR} \\
5 / 8\end{array}$ & bl. sub. média, forte & $\begin{array}{l}\text { duro, m. friável, plástico, } \\
\text { lig. pegajoso }\end{array}$ & $\begin{array}{l}\text { c. peq.; r. gr. e } \\
\text { méd. }\end{array}$ & p.peq., p.gr., r.méd. & Dif. e Hor. \\
\hline $0,96-1,80+$ & Bw3 & Argilosa & $\begin{array}{c}2,5 \mathrm{YR} \\
6 / 8\end{array}$ & bl. sub. média, forte & $\begin{array}{l}\text { duro, m. friável, plástico, } \\
\text { lig. pegajoso }\end{array}$ & $\begin{array}{l}\text { c.peq.; r.gr e } \\
\text { méd. }\end{array}$ & p.peq., r.méd. e gr. & Dif. e Hor. \\
\hline
\end{tabular}



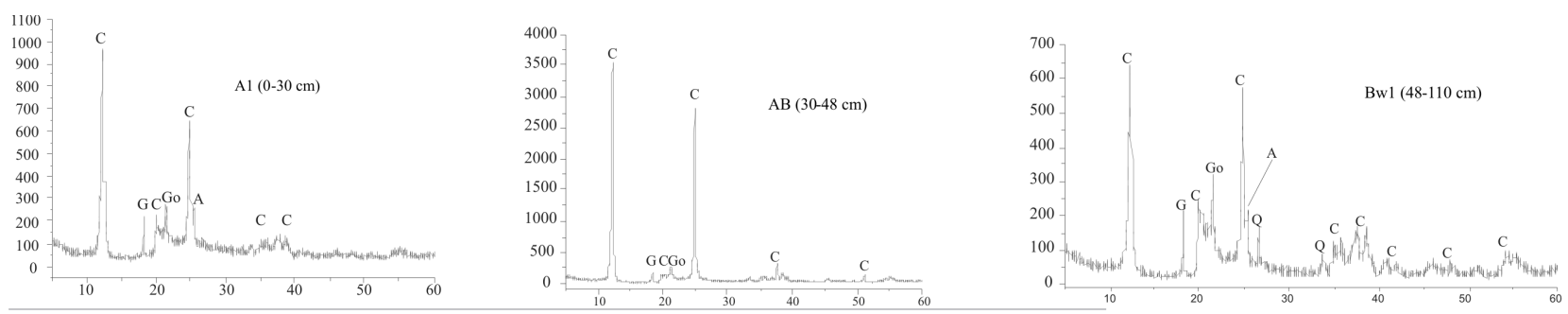

Figura 2 - Difratogramas da fração argila do perfil localizado no topo da topossequência, sendo K = caulinita; $G$ = gibbsita; $Q=$ quartzo; Go = goethita. Ângulo ${ }^{\circ} 2 \theta$ (eixo horizontal); CPS (eixo vertical)
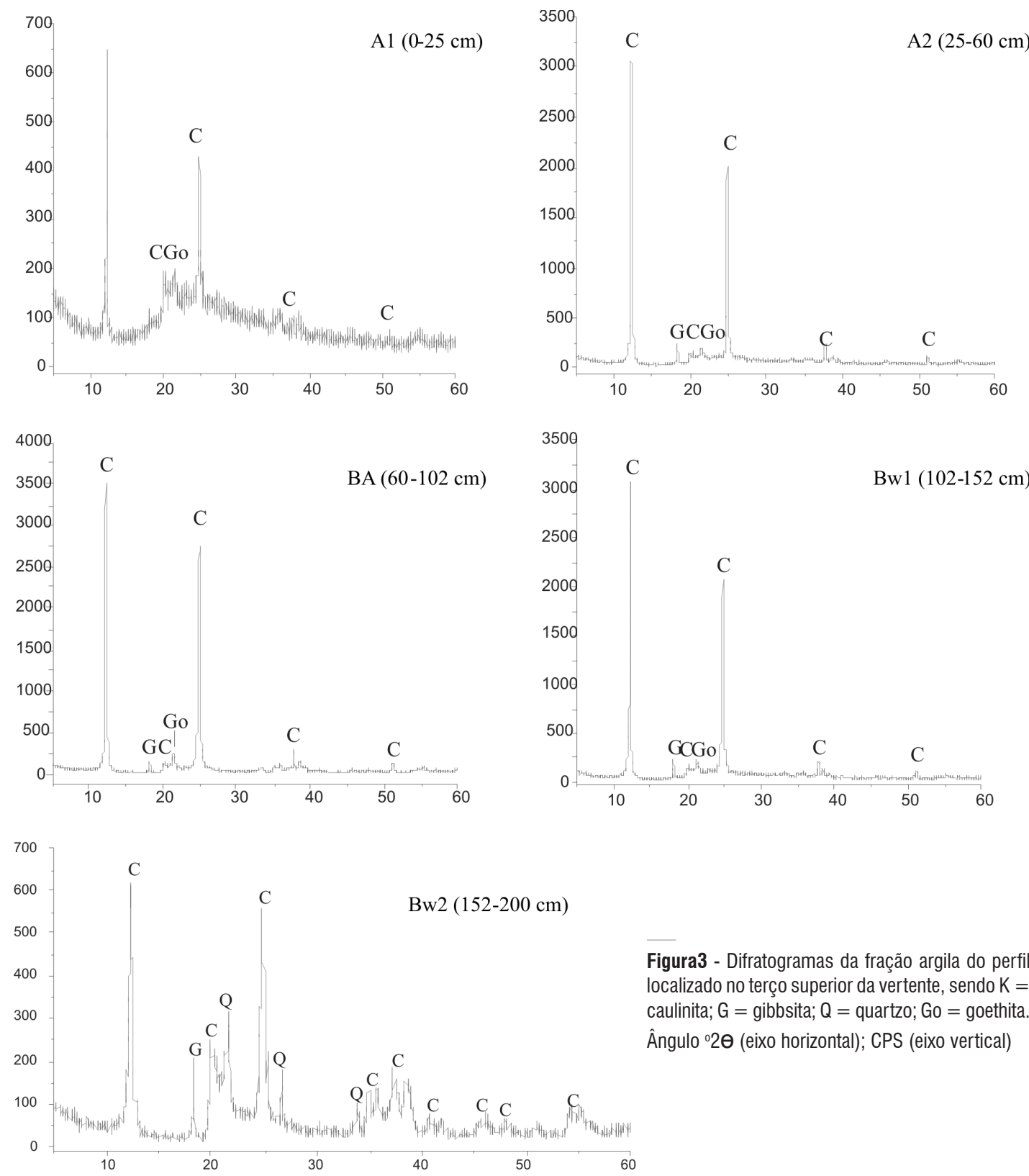

Figura3 - Difratogramas da fração argila do perfil localizado no terço superior da vertente, sendo $K=$ caulinita; $\mathrm{G}=$ gibbsita; $\mathrm{Q}=$ quartzo; $\mathrm{Go}=$ goethita. Ângulo ${ }^{\circ} 2 \theta$ (eixo horizontal); CPS (eixo vertical) 

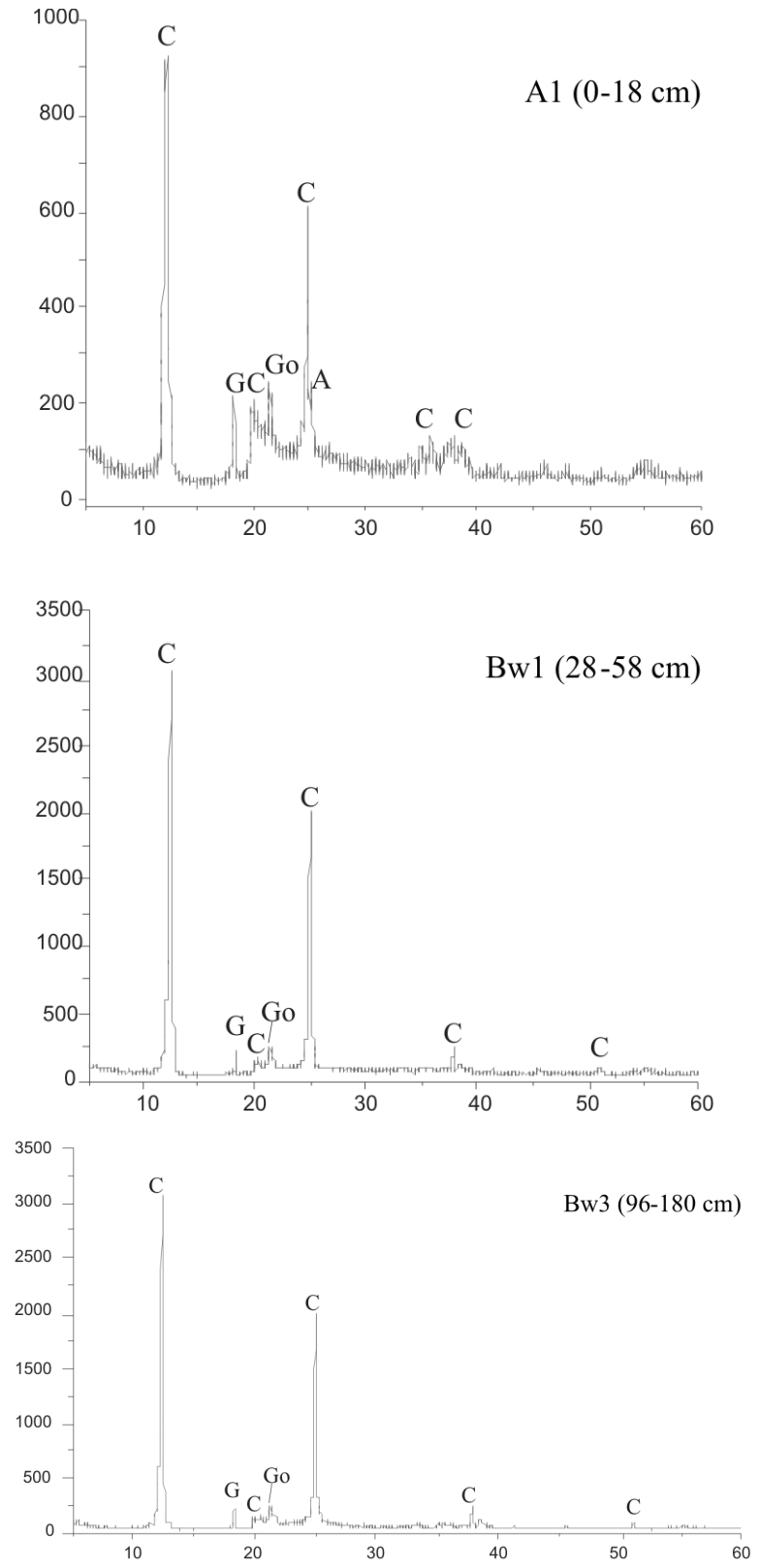

A composição mineralógica e a evolução geoquímica demonstrada deve-se, em parte, ao próprio material de origem, que é um sedimento essencialmente constituído de quartzo, sendo a composição mineralógica das frações grosseiras amplamente dominada por quartzo. A gibbsita e o óxido de ferro foram predominantes, tanto nos horizontes superficiais amarelos, como nos horizontes subsuperficiais vermelhos. Segundo Tardy \& Nahon (1985), a associação quartzocaulinita-goethita é a paragênese mineralógica típica em solos amarelos ou vermelhos, submetidos permanentemente à condiçôes tropicais úmidas. A Serra possui solos pobres em nutrientes (Tabela 2), e com a açâo das chuvas, eles devem
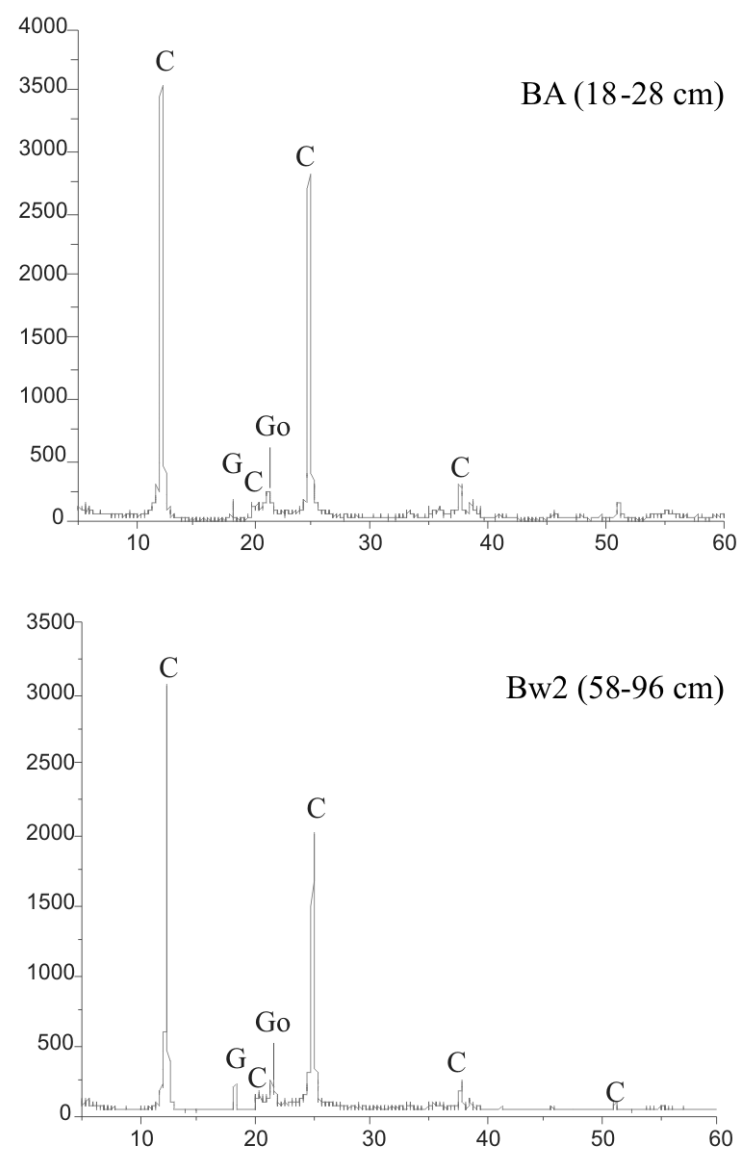

Figura 4 - Difratogramas da fração argila do perfil localizado no terço inferior da encosta da vertente, sendo $\mathrm{K}=$ caulinita; $\mathrm{G}=$ gibbsita; $Q=$ quartzo; $\mathrm{Go}=$ goethita. Ângulo ${ }^{\circ} 2 \Theta$ (eixo horizontal); CPS (eixo vertical)

ter perdido grande parte da sílica, permitindo o aparecimento de alumina e ferro, em constante processo de laterização avermelhada na base da Serra (laterita ferruginosa). Essa laterita possui alta coesão e estabilidade, sendo que a sua remoção por alteração antrópica pode expor o substrato arenítico representado pela Formação Alter do Chão, que na posição dos perfis da vertente é muito friável e passiva de erosão. Os arenitos situados próximo à base da vertente da Serra de Parintins estão protegidos pela vegetação, não estando sujeitos a grandes movimentos de massa e erosóes. Além disso, o clima quente e úmido da região favorece os processos de intemperização de rochas e a lixiviação de metais 
alcalinos e alcalino terrosos; a exposiçáa do solo por longo tempo nessas condiçóes climáticas, aliada às grossas texturas do substrato geológico, permite fácil drenagem da água de percolação, tornando o intemperismo mais intenso (Schubart et al., 1984). Estes solos são formados pela latolização, ou seja, remoção de sílica e bases do perfil (Resende, 1982; Birkeland, 1984). Ocorre migraçáo de sílica e bases do perfil e acúmulo residual de sesquióxidos (gibbsita, goethita, hematita etc) no solum, com ou sem formação de plintita ou concreçáo de ferro (Buol et al., 1980). A presença de plintita nos horizontes subsuperficiais nos perfis P5 e P6 que compóem a vertente (Tabela 3) em evoluçáo para a base atua como uma barreira contra a açáo das águas, evitando o fenômeno de terras caídas na Serra de Parintins.

ATabela 1 apresenta os resultados de log Ko (permeabilidade) ao longo da topossequência. A Ko é dependente de vários atributos do solo, principalmente da densidade e porosidade (macro e microporosidade) (Mesquita \& Moraes, 2004). O acúmulo de carbono na superfície decresceu em profundidade, em maior intensidade nos perfis P4 e P5 (Tabela 1), seguindo a mesma tendência de Ko (Figura 7) permitindo inferir que o sistema radicular constituído por raízes pequenas e finas desses perfis (Tabela 3) promove o seu aumento, pois contribui com translocação da $\mathrm{MO}$ em profundidade e estruturaçấo do solo (Gonçalves \& Mello, 2000). Em Floresta sobre Latossolo Amarelo, as raízes têm importante papel na dinâmica de água nos primeiros $40 \mathrm{~cm}$ do solo; as chuvas freqüentes e a atividade biológica permitem condiçóes favoráveis à absorção da água pelo sistema radicular (Chauvel et al., 1992). Assim, apesar da alta declividade, a permeabilidade das camadas superficiais na vertente é superior ao platô. Nota-se, ainda, que o teor de argila foi a propriedade física que contribuiu para a seqüência: Ko capoeira nova $>$ Ko capoeira 7 anos $>$ Ko floresta densa. Talvez Ko seja mais sensível à mudanças nas propriedades físicas do solo do que as alteraçóes nas coberturas vegetais sobre o solo. Esses Latossolos mesmo quando muito argilosos podem apresentar grande permeabilidade, em decorrência da estrutura. Teixeira (2001), estudando os efeitos do uso da terra sobre as propriedades hidráulicas do solo, por métodos de campo, e em pontos de amostragens pertencentes à classe de Latossolos Amarelos na Amazônia, encontrou valores da Ko variando de 6,62 a $8,41 \mathrm{~cm} \mathrm{dia}^{-1}$. A diferença quando comparada com os encontrados neste estudo pode estar relacionada à vários fatores como: pontos de amostragem e distribuição das raízes (Tabela 3), demonstrando a grande variabilidade dessa propriedade. Marques (2004), estudando parâmetros hídricos na mesma classe de solos sob sistema agroflorestal na Amazônia encontrou valores com variaçôes de 2,62 a 3,20 $\mathrm{cm} \mathrm{dia}^{-1}$, e variaçôes de 1,93 a 3,22 $\mathrm{cm} \mathrm{dia}^{-1}$, em Latossolo Vermelho.
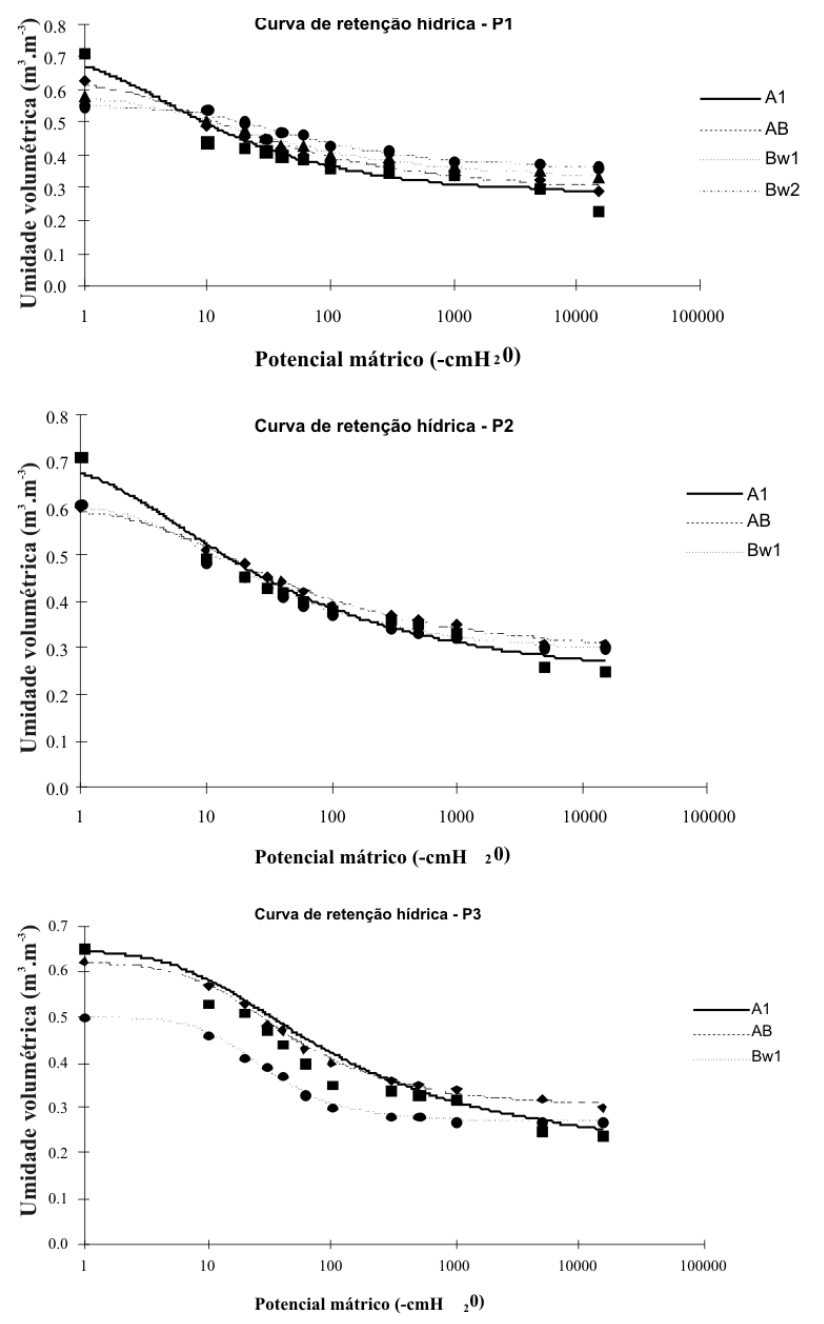

Figura 5 - Curvas de retenção hídrica por horizontes elaboradas para os perfis P1, P2 e P3.

Os resultados referentes às curvas de retenção hídrica são apresentados nas Figuras 5 e 6 . As análises revelam heterogeneidade hídrica entre os perfis localizados no platô e na vertente da paisagem. Com o aumento da profundidade, ocorreu maior retenção de água nos solos. As curvas P1 e P2, P4, P5 e P6 apresentaram as mesmas características estruturais e porais, não sendo observado diferenças no gradiente e na forma entre elas. Entretanto, um deslocamento correspondente à porosidade estrutural $\left(-10 \mathrm{~cm} \mathrm{H}_{2} \mathrm{O}\right.$ a -100 $\mathrm{cmH}_{2} \mathrm{O}$ ) foi observado no P3 (Figura 5), principalmente no horizonte Bw1. Esta forma pode estar relacionada a uma menor microagregaçáo deste horizonte. No geral, observase que as curvas características dos horizontes no platô apresentaram inclinação mais suave ( $>$ retenção de água) devido a estrutura predominante (<macroporosidade) (Tabela 1) e a presença de solos argilosos a muito argilosos (Tabela 3), quando comparado com as da vertente (< retençấo de água) 

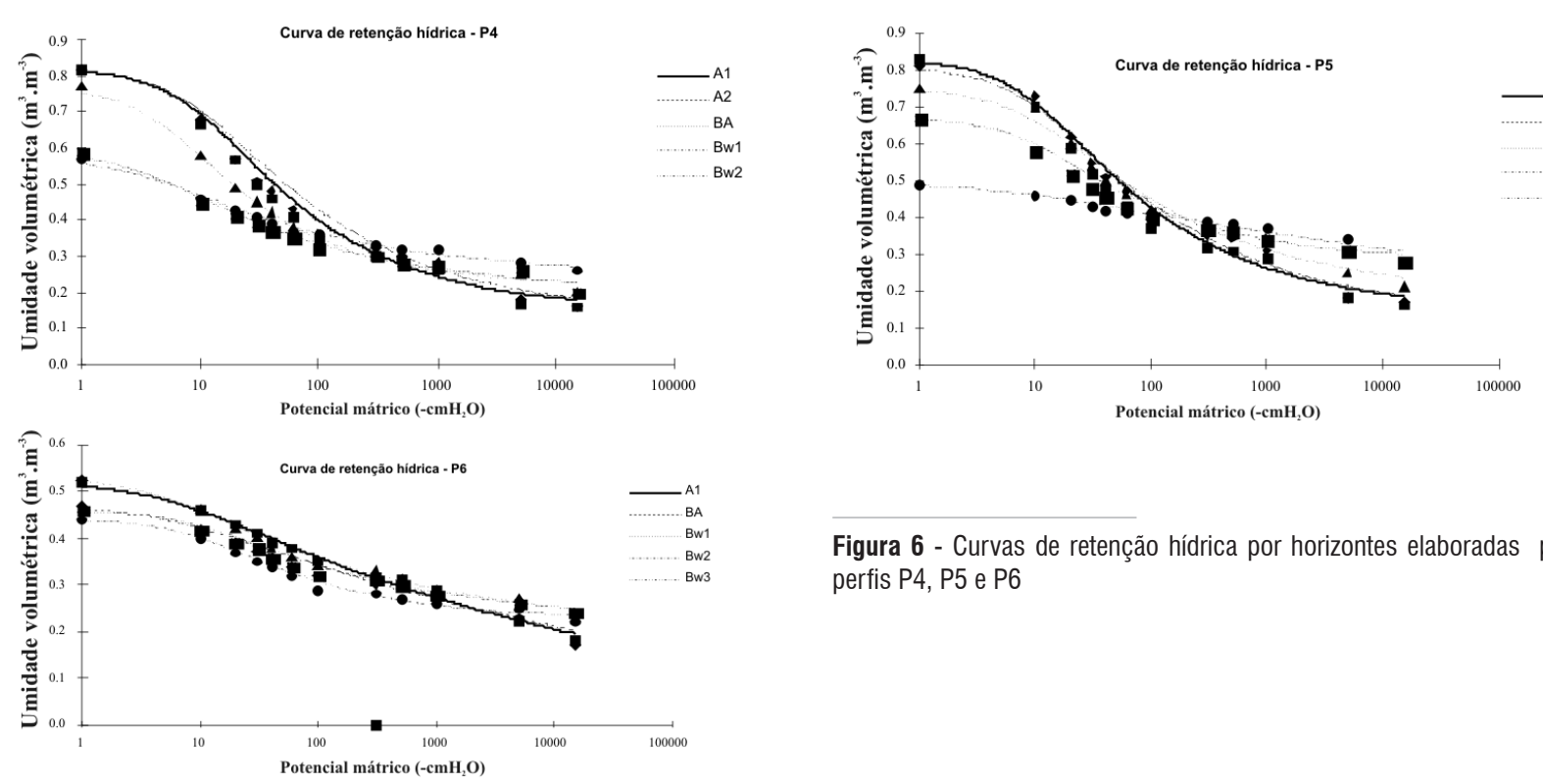

Figura 6 - Curvas de retenção hídrica por horizontes elaboradas para os perfis P4, P5 e P6
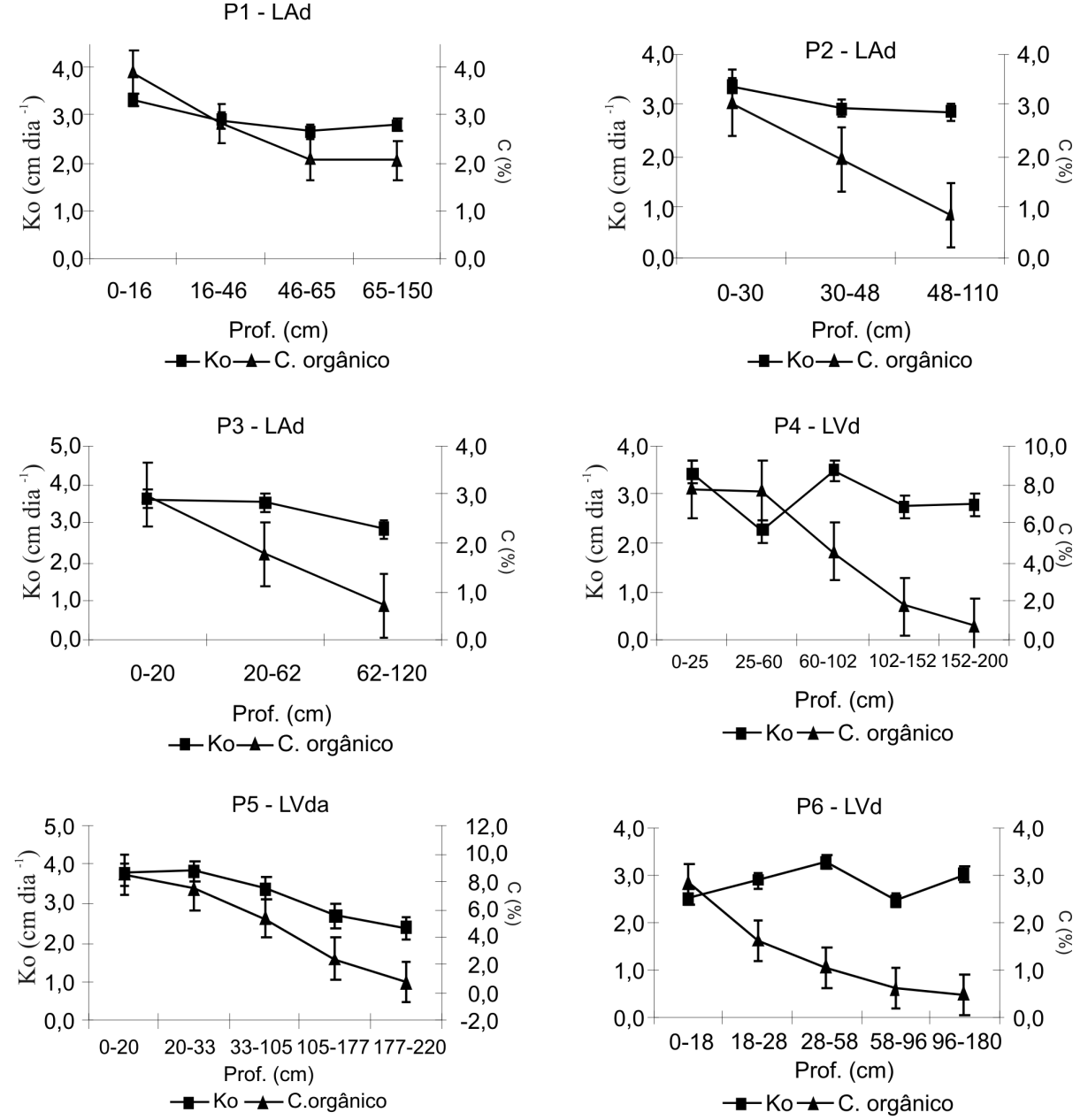

Figura 7 - Variação do carbono orgânico e condutividade hidráulica saturada nos perfis estudados. 
com inclinação mais acentuada. Essas mudanças não estão relacionadas à natureza da argila (mineralogia) dos solos, já que houve uma constância de predomínio da caulinita como argilomineral. Um gradiente maior de umidade volumétrica entre os potenciais baixos $\left(-10 \mathrm{~cm} \mathrm{H}_{2} \mathrm{O}\right.$ a $\left.-100 \mathrm{cmH}_{2} \mathrm{O}\right)$ e altos $\left(-100 \mathrm{~cm} \mathrm{H}_{2} \mathrm{O}\right.$ a $\left.-15000 \mathrm{cmH}_{2} \mathrm{O}\right)$ é observado à medida que a profundidade dos horizontes aumenta (Bw1, Bw2 e Bw3). Em contrapartida, os horizontes A, AB e BA demonstram um gradiente de umidade baixo e médio ao longo dos potenciais. Essa tendência pode ser explicada devido à presença de estrutura dominante microagregada $(\mathrm{Bw})$ e uma porosidade estrutural mais desenvolvida (A, AB e BA) (Figura 5 e 6). Nota-se que a variação topográfica influência a quantidade de água armazenada e disponível nos solos argilosos estudados. A estrutura (> macroporosidade) (Tabela 1) e o maior teor de carbono orgânico obtidos nos perfis P4 e P5 exerceram influência nas tendências das curvas hídricas em baixos potenciais, diferenciando-os dos demais. Analisando a ação da cobertura florestal (Figura 1), aliada à textura média a argilosa (Tabela 3), na superfície dos perfis P4, P5 e P6, foi observado maior agregação do solo e intensidade de poros grandes (Tabela 1 ), que retêm pouca água a $-33 \mathrm{cmH}_{2} \mathrm{O}$, e aumentam a retenção em altas tensóes devido à elevada superfície especifica e capacidade de adsorção da matéria orgânica. A matéria orgânica é considerada como o principal agente de estabilização dos agregados do solo (Castro Filho et al., 1998; Gang Lu et al., 1998).

\section{CONCLUSÕES}

A floresta predominante sobre os perfis do topo e da vertente, promove condiçóes físicas e hídricas adequadas para uma boa agregação, maior intensidade de poros grandes, maior Ko, e melhor retenção hídrica dos solos atuando na sua conservação;

Há acúmulo de carbono na superfície dos solos, decrescendo em profundidade, relacionando-se diretamente com Ko e com o sistema radicular;

A análise mineralógica da fração argila indicou a caulinita como argilomineral predominante, seguido pelos minerais gibbsita, goethita, quartzo e anatásio não havendo variaçóes ao longo da paisagem e relação com as variaçóes nas curvas de retenção hídrica e Ko;

A Serra de Parintins possui um solo deficiente em nutrientes, ácido, textura média a muito argilosa, poroso, com média a alta permeabilidade e plintita nos horizontes subsuperficiais que evitam o fenômeno de terras caídas;

Um gradiente elevado de umidade volumétrica é observado nos horizontes subsuperficiais, havendo mais água retida, quando comparado com horizontes superficiais devido à presença de porosidade textural dominante nos horizontes Bw e uma porosidade estrutural mais desenvolvida nos horizontes superficiais.

\section{AGRADECIMENTOS}

À FAPEAM, pelo financiamento do projeto 811/04. Ao Laboratório de Análise de Física de Solo da EMBRAPA, na pessoa do técnico Estevão Santos e ao Laboratório Temático de Solo e Planta do INPA, precisamente a Tânia Pimentel; pela oportunidade de realização das análises físicas, químicas e hídricas.

\section{BIBLIOGRAFIA CITADA}

Andreola, F.; Costa, R.M.; Olszevski, N. 2004. Influência da cobertura vegetal de inverno e da adubação orgânica e, ou, mineral sobre as propriedades físicas de uma Terra Roxa Estruturada. Revista Brasileira de Ciência do Solo, 24: 857-865.

Berner, E.K.; Berner, R.A. 1987. The Global Water Cycle. New Jersey: Prentice-Hall. 397 p.

Birkeland, P.W. 1984. Soil and Geomorphology. Oxford University Press, New York EUA.

Bravard, S.; Righi, D. 1988. Characteristics of clays in Oxisol Spodosol toposequence in Amazônia (Brazil). Clay Mineralogy, 23: 279-289.

Bravard, S.; Righi, D.1991.Characterization of fulvic and humic acids form an Oxisol-Spodosol toposequence of Amazonia, Brazil. Geoderma, 48: 151-162.

Buol, S.W.; Hole, F.D.; Maccracken, R.J. 1980. Soil Gênesis and classificacion. The Iowa State University Press, Ames. 404 pp.

Castro Filho, C.; Muzilli, O.; Podanoschi, A.L. 1998. Estabilidade dos agregados e sua relação com o teor de carbono orgânico num Latossolo Roxo distrófico, em funçáo de sistemas de plantio, rotaçóes de culturas e métodos de preparo das amostras. Revista Brasileira de Ciência do Solo, 22: 527-538.

Chauvel, A.; Vital, A.R.T.; Lucas, Y.; Desjardins, T.; Franken,W.; Luizao, F.J.; Araguás, L.; Rozanski, K.; Bedmar, A.P. 1992. O papel das raízes no ciclo hidrológico da floresta Amazônica, p. 29-37. In: Anais do VII Congresso Brasileiro de Meteorologia. Sáo Paulo.

Embrapa.1984. Centro Nacional de Pesquisa Agroflorestal. Boletim Agrometeorológico. Manaus, Embrapa - UEPAE. (Documento, 6).

Embrapa. 1997. Manual de Métodos de Análise de Solo. 2a edição. rev. atual. Centro Nacional de Pesquisa de Solos. Rio de Janeiro. 212p. (Embrapa-CNPS. Documentos; 1).

Embrapa. 1999. Manual de Analises Quimicas de Solos, Plantas e Fertilizantes. Embrapa Solos. Brasília: Embrapa comunicação para transferência de tecnologia. $370 \mathrm{p}$.

Fearnside, P.M. 1996. Amazonian deforestation and global warming: Carbon stocks in vegetation replacing Brazil's Amazon forest. Forest Ecology and Management, 80: 21-34.

Fearnside, P.M. 2006. Desmatamento na Amazônia: dinâmica, impactos e controle. Revista Acta Amazônica, 36: 395-400. 
Ferreira, S.J.F.; Luizão, F.J.; F.Miranda, S.A.; Silva, M.S.R. da.; Vital, A.R.T. 2006. Nutrientes na solução do solo em floresta de terra firme na amazônia central submetida à extração seletiva de madeira. Revista Acta Amazônica, 36: 59-68.

Gang, L.U.; Skagami, K.; Tanaka, H.; Hamada, R. 1998. Role of soil organic matter in stabilization of water-stable aggregates in soils under different types of land use. Soil Science Plant Nutrition, 44: $147-155$.

Gonçalves, J.L.M.; Mello, S.L.M. 2000. O sistema radicular das arvores, p. 219-267. In: Gonçaves, J.L.M.; Benedetti, V. (ed). Nutrição e fertilização florestal. Piracicaba: IPEF/FAPESP.

Jordan, C.F. 1986. Soils of the Amazon rainforest, p. 83-94. In: Prance, G.T.; Lovejoy, T.E. (Ed.). Amazonia. Oxford: Pegamon Press.

Lean, J.; Bunton, C.B.; Nobre, C.A.; Rowntree, P.R. 1996. The simulated impact of Amazonian deforestation on climate using measured ABRACOS vegetation characteristics, p. 549-576. In: Gash, J.H.C.; Nobre, C.A.; Roberts, J.M.; Victoria, R.L. Amazonian Deforestation and Climate. Wiley, Chichester, Reino Unido.

Lemos, R.C.; Santos, R.D. dos. 1996. Manual de descriçấo e coleta de solo no campo. $3^{\mathrm{a}} \mathrm{ed}$. Campinas, SP:SBCS/CNPS. $83 \mathrm{pp}$.

Logsdon, S.D.; Jaynes, D.B. 1996. Spatial variability of hydraulic conductivity in a cultivated field at different times. Soil Science Society of America Journal, 60: 703-709.

Lucas, Y.; Luizao, F.J.; Chauvel, A.; Rouiller, J.; Nahon, D. 1993.The relation between biológica activity of the rain forest and mineral composition of soils. Science, 260: 521-523.

Marques, J.D.; Libardi, P.L.; Teixeira, W.G.; Reis, A.M. 2004. Estudo de parâmetros físicos, químicos e hídricos de um Latossolo Amarelo, na região Amazônica. 2004. Acta Amazônica, 34: 145-154.

Mesquita, M.G.B.F.; Moraes, S.O. 2004. A dependência entre a condutividade hidráulica saturada e atributos físicos do solo. Ciência Rural, 34: 963-969.

Ruthenberg, H. 1980. Farming systems in the tropics. Clarendon Press, Oxford, 3rd ed., 424 pp.
Schaefer, C.E.G.R. 1996. The Microstructure Of Latossols as LongTerm Biotic Contructs. In: XIII Congresso Latino Americano de Ciência do Solo, 1996, Águas de Lindóia. Resumos Expandidos.

Schubart, H.O.R.; Franken, W.; Luizão, F.J. 1984. Uma floresta sobre solos pobres. Ciência Hoje, 2: 26-32.

Stallard, R.F.; Edmond, J.M. 1981. Geochemistry of the Amazon. 1. Precipitation chemistry and the marine contribution to the dissolved-load at the time of peak discharge. Journal Of Geophysical Research-Oceans And Atmospheres, 86: 9844-9858.

Teixeira, W.G. 2001. Land use effects on Soil Physical and Hydraulic Properties of a Clayey Ferralsol in the Central Amazon. Tese de Doutorado, University of Bayreuth, Bayreuth, Alemanha. 255pp.

Tardy, Y.; Nahon, D. 1985. Geochemistry of laterites, stability of Al-goethite, Al-hematite, and $\mathrm{Fe}^{3+}$ kaolinite in bauxites and ferricretes: an approach to the mechanism of concretion formation. American Journal of Science, 285: 865-903.

Tomasella, J.; Hodnett, M.G. 1996. Soil hydraulic properties and van Genuchten parameters for an oxisol under pasture in Central Amazônia. In: Gash, J.H.C.; Nobre, C.A.; Roberts, J.M.; Victoria, R.L.. (Org.). Amazonian Deforestation and Climate. Chichester, UK, p. 101-124.

Vieira, L.S.; Santos, P.C.T.C. 1987. Amazônia: seus solos e outros recursos naturais. São Paulo: Ceres. 416pp.

Youngs, E.G. 1991. Hydraulic conductivity of saturated soils, p. 161-207. In: Smith, K.A.; Mullins, C.E. (Ed). Soil analysis: physical methods. Marcel Dekker, New York.

Wilkinson, L. 1998. Systat: The system for statistics. Evanston, IL, Systat Inc.

Recebido em 23/11/2007

Aceito em 14/10/2009 